\title{
EXPLICIT TRACES OF FUNCTIONS FROM SOBOLEV SPACES AND QUASI-OPTIMAL LINEAR INTERPOLATORS
}

\author{
DANIEL ESTÉVEZ
}

Abstract. Let $\Lambda \subset \mathbb{R}$ be a strictly increasing sequence. For $r=1,2$, we give a simple explicit expression for an equivalent norm on the trace spaces $\left.W_{p}^{r}(\mathbb{R})\right|_{\Lambda},\left.L_{p}^{r}(\mathbb{R})\right|_{\Lambda}$ of the non-homogeneous and homogeneous Sobolev spaces with $r$ derivatives $W_{p}^{r}(\mathbb{R}), L_{p}^{r}(\mathbb{R})$. As Fefferman, Israel and Luli show, such simple result is impossible for Sobolev spaces of $\mathbb{R}^{d}$ for $d \geqslant 2$.

We also construct an interpolating spline of low degree having optimal norm up to a constant factor. This spline and the equivalent trace norm are very easy to compute. We also conjecture, what is the expression for the equivalent trace norm for any $r \geqslant 1$ and give some partial results, which, in particular, confirm this conjecture.

Mathematics subject classification (2010): Primary 46E35, Secondary 41A15, 58C25. polation.

Keywords and phrases: Bounded linear extension operator, Sobolev spaces, trace norm, spline inter-

\section{REFERENCES}

[1] K. E. AtKinson, An introduction to numerical analysis, 2nd ed., John Wiley \& Sons Inc., New York, 1989.

[2] D. Azagra, C. Mudarra, On a Whitney extension problem for convex functions, avialable at arXiv:1501.05226v4 [math.CA].

[3] Yu. BRUdnyi And P. A. ShVARTSMan, Whitney's extension problem for multivariate $C^{1, \omega}$ functions, Trans. Amer. Math. Soc. 353 (2001), no. 6, 2487-2512.

[4] C. L. Fefferman, A sharp form of Whitney's extension theorem, Ann. of Math. (2) 161 (2005), no. $1,509-577$.

[5] C. L. FefFERMAN, Interpolation and extrapolation of smooth functions by linear operators, Rev. Mat. Iberoamericana 21 (2005), no. 1, 313-348.

[6] C. L. FefFerman, Whitney's extension problem for $C^{m}$, Ann. of Math. (2) 164 (2006), no. 1, 313 359.

[7] C. L. FefFerman, Whitney's extension problems and interpolation of data, Bull. Amer. Math. Soc. (N. S.) 46 (2009), no. 2, 207-220.

[8] C. L. Fefferman, A. Israel, And G. K. Luli, Sobolev extension by linear operators, J. Amer. Math. Soc. 27 (2014), no. 1, 69-145.

[9] C. L. Fefferman, A. IsRael, G. K. Luli, The structure of Sobolev extension operators, Rev. Mat. Iberoam. 30 (2014), no. 2, 419-429.

[10] C. L. Fefferman, A. Israel, G. K. Luli, Fitting a Sobolev function to data, Part I in Rev. Mat. Iberoam. 32 (2016), no. 1, 275-376; Part II in Rev. Mat. Iberoam. 32 (2016), no. 2, 649-750; Part III to appear in Rev. Mat. Iberoam.

[11] C. L. Fefferman And B. Klartag, Fitting a $C^{m}$-smooth function to data, I, Ann. of Math. (2) 169 (2009), no. 1, 315-346.

[12] C. L. FefFerman and B. Klartag, Fitting a $C^{m}$-smooth function to data, II, Rev. Mat. Iberoam. 25 (2009), no. 1, 49-273.

[13] B. G. Gabdulkhaev, L. B. Ermolaeva, Lagrange interpolation polynomials in Sobolev spaces, (Russian) Izv. Vyssh. Uchebn. Zaved. Mat. 1997, no. 5, 7-19; translation in Russian Math. (Iz. VUZ) 41 (1997), no. 5, 4-16. 
[14] B. G. GabdulkhaEv, L. B. ERmolaEva, Interpolation over extreme points of Chebyshev polynomials and its applications, (Russian) Izv. Vyssh. Uchebn. Zaved. Mat. 2005, no. 5, 22-41; translation in Russian Math. (Iz. VUZ) 49 (2005), no. 5, 19-37 (2006).

[15] A. IsRAel, A bounded linear extension operator for $L^{2, p}\left(\mathbb{R}^{2}\right)$, Ann. of Math. (2) 178 (2013), no. 1, 183-230.

[16] G. K. LuLI, Whitney extension for $W^{k, p}(E)$ in one dimension, (2008), Notes available at http://users.math.yale.edu/ ${ }^{\sim}$ gk16/papers/notes.pdf.

[17] G. K. LuLI, $C^{m, \omega}$ extension by bounded-depth linear operators, Adv. Math. 224 (2010), no. 5, $1927-$ 2021.

[18] P. A. ShVARTSman, On extensions of Sobolev functions defined on regular subsets of metric measure spaces, J. Approx. Theory 144 (2007), no. 2, 139-161.

[19] P. A. Shvartsman, Sobolev $W_{p}^{1}$-spaces on closed subsets of $\mathbf{R}^{n}$, Adv. Math. 220 (2009), no. 6, 1842-1922.

[20] P. A. ShVARTSman, Lipschitz spaces generated by the Sobolev-Poincaré inequality and extensions of Sobolev functions, avialable at arXiv:1310.0795 [math.FA].

[21] P. A. ShVARTsman, Sobolev $L_{p}^{2}$-functions on closed subsets of $\mathbf{R}^{2}$, Adv. Math. 252 (2014), 22-113.

[22] H. Whitney, Differentiable functions defined in closed sets, I, Trans. Amer. Math. Soc. 36 (1934), no. $2,369-387$. 